\title{
Accurate Mass Precursor Ion Data and Tandem Mass Spectrometry Identify a Class I Human Leukocyte Antigen A*0201-Presented Peptide Originating from Vaccinia Virus
}

\author{
Kenneth L. Johnson
}

The W. M. Keck FT-ICR Mass Spectrometry Laboratory, and Mayo Proteomics Research Center, Mayo Clinic College of Medicine, Rochester, Minnesota, USA

Inna G. Ovsyannikova

Mayo Vaccine Research Group, Mayo Clinic College of Medicine, Rochester, Minnesota, USA

Benjamin J. Madden

The W. M. Keck FT-ICR Mass Spectrometry Laboratory, and Mayo Proteomics Research Center, Mayo Clinic College of Medicine, Rochester, Minnesota, USA

Gregory A. Poland*

Mayo Vaccine Research Group, Mayo Clinic College of Medicine, Rochester, Minnesota, USA

David C. Muddiman ${ }^{+}$

The W. M. Keck FT-ICR Mass Spectrometry Laboratory, and Mayo Proteomics Research Center, Mayo Clinic College of Medicine, Rochester, Minnesota, USA

We have used accurate mass precursor ion data generated on a hybrid linear-ion trap-Fourier transform ion cyclotron resonance mass spectrometer to augment tandem mass spectrometry (MS/MS) data generated on two different instrument types. Results from these experiments have allowed us for the first time to identify a naturally processed peptide presented by a class I human leukocyte antigen allele (HLA-A*0201) that was isolated from B cells infected by live vaccinia, the viral agent of the smallpox vaccine. The accurate mass data, in conjunction with MS/MS data, was able to identify the sequence IVIEAIHTV (aa 187-195) from the protein thymidylate kinase of vaccinia, distinguishing it from a similar sequence IVLEAIAEH: a "self-peptide" from the human protein phospholipase $C \beta 3$. Accurate mass data for the doubly charged species from the naturally processed and presented peptide was 497.8006 , which was within $0.8 \mathrm{ppm}$ of the calculated $\mathrm{m} / \mathrm{z}$ of 497.8002, while being $-37.3 \mathrm{ppm}$ from the calculated $\mathrm{m} / \mathrm{z}(497.7820)$ of the second-ranked peptide sequence IVLEAIAEH. Accurate mass data ranged from less than 0.1 to $1.2 \mathrm{ppm}$ for other peptides identified in this sample. A BLAST search shows this sequence, IVIEAIHTV, is conserved in the same protein of a number of other orthopoxviruses, including the variola (smallpox) virus. Additionally, accurate mass data were able to uncover a false positive search result that was not distinguished by scoring of the match to the MS/MS data. (J Am Soc Mass Spectrom 2005, 16, 1812-1817) (c) 2005 American Society for Mass Spectrometry

$\mathrm{A}$ dvances in mass spectrometry instrumentation and associated analytical methods have led to unprecedented growth in the application of mass spectrometry to research in the life sciences. The development of electrospray ionization [1], advances in miniaturized chromatography $[2,3]$, tandem mass spectrometry (MS/MS) of peptides [4], and multidimen-

Published online September 26, 2005

Address reprint requests to David C. Muddiman, W. M. Keck FT-ICR Mass Spectrometry Laboratory, Department of Chemistry, North Carolina State University, Raleigh, NC 27695, USA. E-mail: david_muddiman@ncsu.edu *Also at the Program in Translational Immunovirology and Biodefense, Mayo Clinic College of Medicine, Rochester, Minnesota.

tAlso at the Department of Biochemistry and Molecular Biology, Mayo Clinic College of Medicine, Rochester, Minnesota. sional liquid chromatography (LC) separations $[5,6]$ have successively enabled other researchers in the application of mass spectrometry to their respective areas of research. As an example, we have employed the use of multidimensional LC together with automated acquisition of MS/MS data for the identification of selfpeptides and peptides originating from measles virus proteins that were displayed by the human leukocyte antigen (HLA) class II system from cultured B cells infected with measles virus [7-9].

Recently, the development and commercialization of hybrid mass spectrometers incorporating Fourier transform ion cyclotron resonance (FTICR) analyzers, with high resolving power (RP) and high mass accuracy offer additional opportunities to enhance the usefulness of 
mass spectrometry in biological research $[10,11]$. As a result, the effectiveness of combining accurate mass data from the precursor ion with MS/MS data has been reported $[12,13]$.

This report describes an example where the high mass accuracy of a hybrid two dimensional (2D)-ion trapFTICR-mass spectrometry (MS) instrument combined with MS/MS data enables confident sequence assignment of a naturally processed and presented class I peptide originating from vaccinia, the viral agent used in the smallpox vaccine, and distinguishing it from a similar sequence from the human protein phospholipase $C \beta 3$.

T-helper cells play an important role in orchestrating the effector function of cytotoxic T lymphocytes (CTLs) in immunity against orthopoxvirus infection. Only a few vaccinia virus class I peptides and HLA-A*0201restricted $\mathrm{CD}^{+} \mathrm{T}$ cells are described in the literature [14-16]; however, no naturally processed and presented vaccinia virus T-cell epitopes have been identified. One major obstacle is the size of the virus. Vaccinia is a large, double-stranded virus, which replicates in the nucleus of infected cells, with an $\sim 200$-kilobase-pair (kbp) DNA genome, encoding more than 230 open reading frames and expressing more than 200 proteins [17, 18]. In addition, information about immunodominant orthopoxvirus antigens and epitope specificities of virusspecific CTL responses is still lacking [14]. "Therefore, the role of specific peptides presented in the context of HLA molecules to $T$ cells can be considered as one of the most important fundamental questions for understanding immune responses to vaccinia and other orthopoxviruses. In this study, we report a new naturally processed and HLA-A*0201-presented peptide epitope derived from vaccinia virus, which is encoded by the vaccinia virus gene thymidylate kinase (TmpK) and is highly conserved in vaccinia, variola, and other orthopoxviruses.

\section{Experimental}

\section{Vaccinia Infection of B Cells}

The New York City Board of Health vaccine-strain of vaccinia virus (Dryvax ${ }^{\mathrm{TM}}$ ) was cultured in HeLa cells in Dulbecco's modified Eagle's medium, supplemented with $5 \%$ fetal calf serum (virus stocks of $6.3 \times 10^{8}$ plaque-forming units $[\mathrm{pfu}] / \mathrm{mL})$. An established Epstein-Barr virus-transformed human HLA-A*0201 homozygous cell line, Priess (cell ID no. 11,277; European Collection of Cell Cultures, Salisburg, Wiltshire, UK) was used for this study. Cells were infected with live vaccinia virus at a multiplicity of infection of 0.1 pfu/cell for $2 \mathrm{~h}$ and maintained for $24 \mathrm{~h}$ at $37^{\circ} \mathrm{C}$. The uninfected and vaccinia-infected cells were used for obtaining cell lysates for purification of HLA-A2 molecules. Equal-sized batches of uninfected and vacciniainfected cells were prepared, washed in phosphatebuffered saline, pelleted, and stored at $-80{ }^{\circ} \mathrm{C}$ for isolation of HLA-A*0201 molecules and HLA-A*0201- bound peptides. Infection of cells with vaccinia was confirmed by flow cytometry using a polyclonal antivaccinia antibody specific for vaccinia proteins (Fitzgerald Industries International, Inc., Concord, MA), followed by a fluorescein isothiocyanate-conjugated secondary antibody (data not shown).

\section{Production of HLA-A2 Monoclonal Antibodies and Construction of Immunoaffinity Column}

The PA2.1 hybridoma (ATCC, Manassas, VA) was the source of HLA-A2-reactive monoclonal antibody $(\mathrm{mAb})$. PA2.1 hybridoma cells $\left(1 \times 10^{5} / \mathrm{mL}\right)$ were cultured for 2-3 days in modified Dulbecco's medium. The hybridoma supernatants were collected, and immunoglobulin G (IgG) antibodies were purified using a protein G-Sepharose fast flow column (Pharmacia, Peapack, NJ). Immunoaffinity columns were constructed using protein A-Sepharose (Sigma-Aldrich Corp., St. Louis, MO), covalently coupled to the purified HLAA2-specific mAb (PA2.1, IgG1). For coupling, $20 \mathrm{mM}$ of dimethyl pimelimidate dihydrochloride (DMP) was used. Briefly, $7.5 \mathrm{~mL}$ of protein A-Sepharose was washed in $20 \mathrm{~mL}$ of $100-\mathrm{mM}$ borate buffer, $\mathrm{pH} 8.2$. Anti-HLA-A2 mAb (1.66 mg/mL) was diluted $(15 \mathrm{mg}$

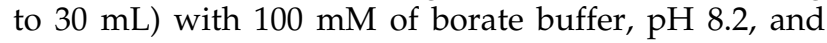
mixed with Sepharose for $30 \mathrm{~min}$. After incubation, the Sepharose beads were spun at $1500 \mathrm{rpm}$ and protein concentration of the supernatant was measured at 280 $\mathrm{nm}$. Sepharose was poured into the column with sintered glass and was washed with $100 \mathrm{mM}$ of borate buffer, pH 8.2, and $200 \mathrm{mM}$ of triethanolamine, $\mathrm{pH}$ 8.2. Protein A-Sepharose then was coupled with fresh 20 $\mathrm{mM}$ of DMP in $200 \mathrm{mM}$ of triethanolamine, $\mathrm{pH}$ 8.2, for $45 \mathrm{~min}$ by rocking and washing with $20 \mathrm{~mL}$ of $20-\mathrm{mM}$ ethanolamine to block residues. Finally, Sepharose beads were washed with $100 \mathrm{mM}$ of borate buffer, $\mathrm{pH}$ 8.2 , and equilibrated with $0.1 \%$ Nonidet- 40 and $10 \mathrm{mM}$ of Tris, $\mathrm{pH} 8.0$.

\section{Isolation of HLA-A*0201-Associated Peptides}

Uninfected and vaccinia-infected B cells were solubilized in $20 \mathrm{mM}$ of Tris, $\mathrm{pH} 8.0,150 \mathrm{mM}$ of $\mathrm{NaCl}, 1 \%$ CHAPS (N,N-Dimethyl-N-(3-sulfopropyl)-3-[[(3 $\alpha, 5 \beta$, $7 \alpha, 12 \alpha)$-3,7,12-trihydroxy-24-oxocholan-24-yl]amino]1-propanaminium inner salt; 3-[(3-cholamidopropyl)dimethylammonio]-1-propanesulfonate) $2 \mathrm{mM}$ of phenylmethylsulfonyl fluoride, $100 \mu \mathrm{M}$ of iodoacetamide, aprotinin $(5 \mu \mathrm{g} / \mathrm{mL})$, leupeptin $(10 \mu \mathrm{g} / \mathrm{mL})$, pepstatin A $(10 \mu \mathrm{g} / \mathrm{mL})$, ethylenediaminetetraacetic acid (3 ng/ $\mathrm{mL})$, and $0.2 \%$ sodium azide. After sample centrifugation at $100,000 \mathrm{~g}$ for $1 \mathrm{~h}$, supernatants were passed through an immunoaffinity column with HLA-A2.1specific mAb (PA2.1) and protein A-Sepharose. HLA-A2 molecules were eluted from the column with $50 \mathrm{mM}$ of diethylamine, $\mathrm{pH} 11.5,0.4 \%$ n-octylglucoside, $150 \mathrm{mM}$ of $\mathrm{NaCl}$, and $0.02 \% \mathrm{NaN}_{3}$. Eluates were neutralized with $1 \mathrm{M}$ Tris, $\mathrm{pH} 6.8$, and concen- 
trated to $1 \mathrm{mg} / \mathrm{mL}$ by ultrafiltration (Centriprep 10; Amicon Corp., Danvers, MA). Acetic acid (14\%) was used to dissociate any bound peptides from HLA-A2 molecules. The peptides were stored at $-80{ }^{\circ} \mathrm{C}$ for later analysis by mass spectrometry.

\section{Desalting Peptides}

Before 2D-LC, HLA class I peptides were desalted on a $1 \mathrm{~mm}$ i.d. (inner diameter) by $10 \mathrm{~mm}$ long reversedphase cartridge (PeptideTrap; Michrom BioResources, Inc., Auburn, CA), vacuum-concentrated to $\sim 10 \mu \mathrm{L}$, and diluted with $15 \mu \mathrm{L}$ of water/acetonitrile/n-propanol/ formic acid (98.5/1/0.5/0.2 by volume) also containing $0.0005 \%$ heptafluorobutyric acid and $0.5 \mathrm{mM}$ of ammonium acetate.

\section{Strong Cation Exchange Fractionation}

Strong cation exchange (SCX) separations were performed using a 0.5-mm i.d. by $150 \mathrm{~mm}$ long Polysulfoethyl A column (Michrom BioResources, Inc.) at a flow rate of $25 \mu \mathrm{L} / \mathrm{min}$. A gradient of $5 \mathrm{mM}$ of $\mathrm{KH}_{2} \mathrm{PO}_{4}(\mathrm{pH}$ $3.1) / 10 \%$ acetonitrile into $500 \mathrm{mM}$ of $\mathrm{KCl}$ (in the same phosphate/acetonitrile buffer) was used to fractionate peptides at 1 -min intervals. The mobile phase gradient started at $0 \%$ B with linear gradients to $20 \%$ B at $20 \mathrm{~min}$ and $80 \% \mathrm{~B}$ at $30 \mathrm{~min}$, followed by a $5-\mathrm{min}$ hold at $80 \%$ $\mathrm{B}, 5 \mathrm{~min}$ to return to $0 \% \mathrm{~B}$, and a 15 -min re-equilibration period (50 min total method). A 1-m length of $100 \mu \mathrm{m}$ i.d. fused silica (8 $\mu \mathrm{L}$ volume, 0.33 min delay at 25 $\mu \mathrm{L} / \mathrm{min}$ ) was used to collect fractions via a Gilson FC 203B fraction collector.

\section{Quadrupole Time-of-Flight LC-MS/MS Analyses}

Initial automated LC-MS/MS analyses were done on a CapLC interfaced with a Q-ToF II (Waters Corp., Bedford, MA), using a $24-\mathrm{cm}$ by $75 \mu \mathrm{m}$ i.d. column packed in-house with Targa C18 (Higgins Analytical, Mountain View, CA). The autosampler loaded $10-\mu \mathrm{L}$ aliquots of SCX fractions onto a $0.25-\mu \mathrm{L}$ precolumn (Optimize Technologies, Oregon City, OR), custom-packed with Michrom Magic C8, $5 \mu \mathrm{m}, 300 \AA$ (Michrom BioResources, Inc.), which was inserted into a Cheminert 10-port switching valve (Valco Instruments Co., Inc., Houston, TX). Mobile phase A was water/acetonitrile/ $n$-propanol/formic acid (98/1/1/0.2 by volume) and mobile phase $\mathrm{B}$ was acetonitrile/n-propanol/water/ formic acid (80/10/10/0.2 by volume). A gradient from $3-50 \%$ B over $60 \mathrm{~min}$ was used at an approximate column flow of $0.2 \mu \mathrm{L} / \mathrm{min}$. Pump C on the CapLC was used to transfer samples from the autosampler to the precolumn, using a $10-\mu \mathrm{L} / \mathrm{min}$ flow of water/acetonitrile/ $n$-propanol/formic acid $(98 / 1 / 1 / 0.2$ by volume) that additionally contained $0.5 \mathrm{mM}$ of ammonium acetate. A 10-min transfer period $(100 \mu \mathrm{L})$ was used to transfer the sample and wash potassium salts from the peptides before switching the precolumn in line with the LC column and starting the reversed-phase gradient.
Automated MS/MS measurements were performed on the three most intense doubly charged ions, using charge and $m / z$-dependent selection of collision energies. MS/MS spectra were searched against the NCBI nr (National Center for Biotechnology Information, nonredundant) database using MASCOT software, without enzyme constraints, using a precursor mass window of 0.3 mass units and a fragment ion mass window of 0.2 mass ${ }^{\mathrm{T}}$ Units ${ }^{\mathrm{T}}[19]$.

\section{Hybrid Linear Ion Trap Quadrupole-FTICR LC-MS/MS Analyses}

Accurate mass LC-FTICR-MS/MS measurements were performed on a ThermoFinnigan LTQ-FT (ThermoElectron, Bremen, Germany). A Michrom Paradigm LC (Michrom BioResources) plumbed with a 75- $\mu \mathrm{m}$ i.d. by 5 -cm length Integrafrit column packed with ProteoPep II (New Objective, Woburn, MA) was used for the LC separation. The sample was loaded on a $0.3-\mathrm{mm}$ i.d. by $1-\mathrm{mm}$ long precolumn packed with PepMap stationary phase (Dionex, Sunnyvale, CA).

The LTQ-FT was operated in a data-dependent mode similar ${ }^{\mathrm{T}} \mathrm{tb}^{\mathrm{T}}$ that ${ }^{\mathrm{T}}$ described ${ }^{\mathrm{T}} \mathrm{th}^{\mathrm{T}} \mathrm{O} / \mathrm{sen}^{\mathrm{T}} \mathrm{et}^{\mathrm{TM}} \mathrm{al} .{ }^{\mathrm{T}}[\mathrm{H} 3]$, ${ }^{\mathrm{T}}$ where ${ }^{\mathrm{T}} \mathrm{a}$ medium RP $(25,000$ full width at half maximum FWHM at $m / z$ 400) scan from $m / z 375-1600$ was acquired in the FTICR analyzer, followed by a high RP (RP $=50,000$ FWHM at $m / z$ 400) FTICR SIM scan over a $10 \mathrm{~m} / \mathrm{z}$ window, with linear-ion trap collision induced dissociation (CID) experiments on the top three most abundant

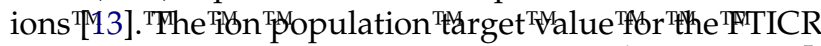
full scan and SIM scan were set at $3 \times 10^{6}$ and $1 \times 10^{5}$, respectively. For MS/MS experiments the ion trap target population was set to $1 \times 10^{5}$; collision energy was set to $35 \%$.

\section{Results and Discussion}

Among the highly polymorphic human HLA class I molecules we chose the HLA-A*0201 allele, part of the HLA-A2 supertype, to search for $\mathrm{CD}^{+}$vaccinia virus T-cell epitopes because the HLA-A2 supertype is extremely prevalent in the general population $(\sim 50 \%)$

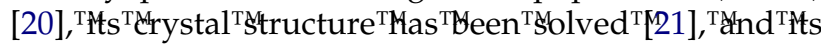

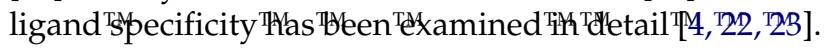
We infected a Class I HLA-A*0201 homozygous cell line with live vaccinia virus, and then searched for naturally processed and presented vaccinia virus-derived peptides.

Initial Mascot search results of MS/MS spectra generated by the Q-Tof II identified self-peptides and peptides unique to bovine albumin, the latter attributed to the fetal calf serum used to culture the B cells from which peptides were harvested. In addition, an MS/MS spectrum from SCX fraction 21 was tentatively identified as IVIEAIHTV (aa 187-195) from the protein TmpK of vaccinia virus, the immunogenic agent in the smallpox vaccine. TmpK catalyzes a critical step in the biosynthesis of (deoxy)thymidine triphosphate and is 

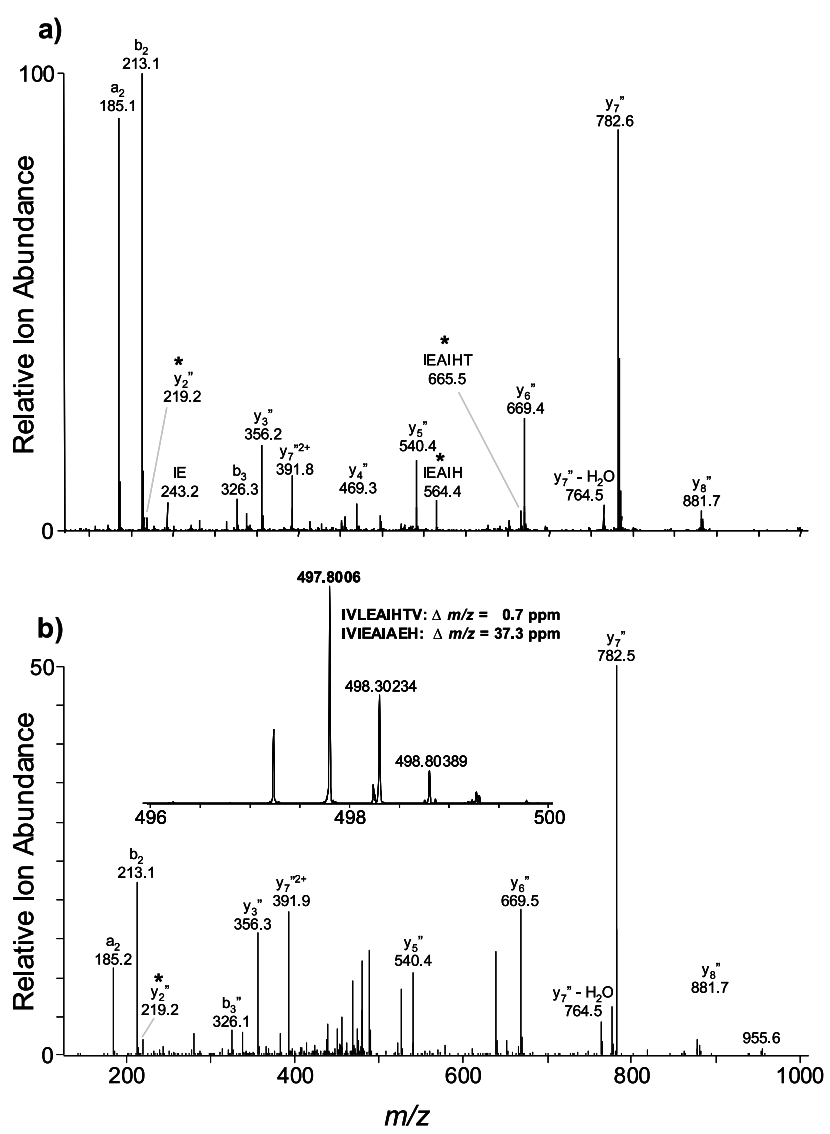

Figure 1. MS/MS and FTICR-MS data for a class I peptide identified as IVIEAIHTV from TmpK of vaccinia. (a) Q-ToF II MS/MS spectrum (collision energy $=-18 \mathrm{~V}$. (b) MS/MS spectrum from a linear-ion trap-FTICR hybrid instrument (LTQ-FT). MS/MS ions marked with an asterisk $\left(^{*}\right)$ denote fragmentation products that distinguish the sequence IVIEAIHTV from IVLEAIEAH. All other labeled fragment ions support both sequences. The inset of panel (b) shows the FTICR accurate mass spectrum of the doubly charged precursor ion that conclusively identifies the correct sequence as IVIEAIHTV.

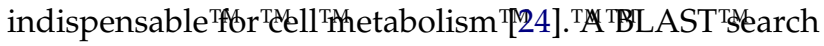
shows this sequence is conserved across a number of other poxvirus families.

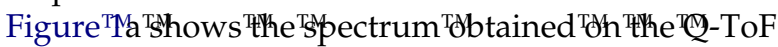
II. The MS/MS search results were not conclusive:
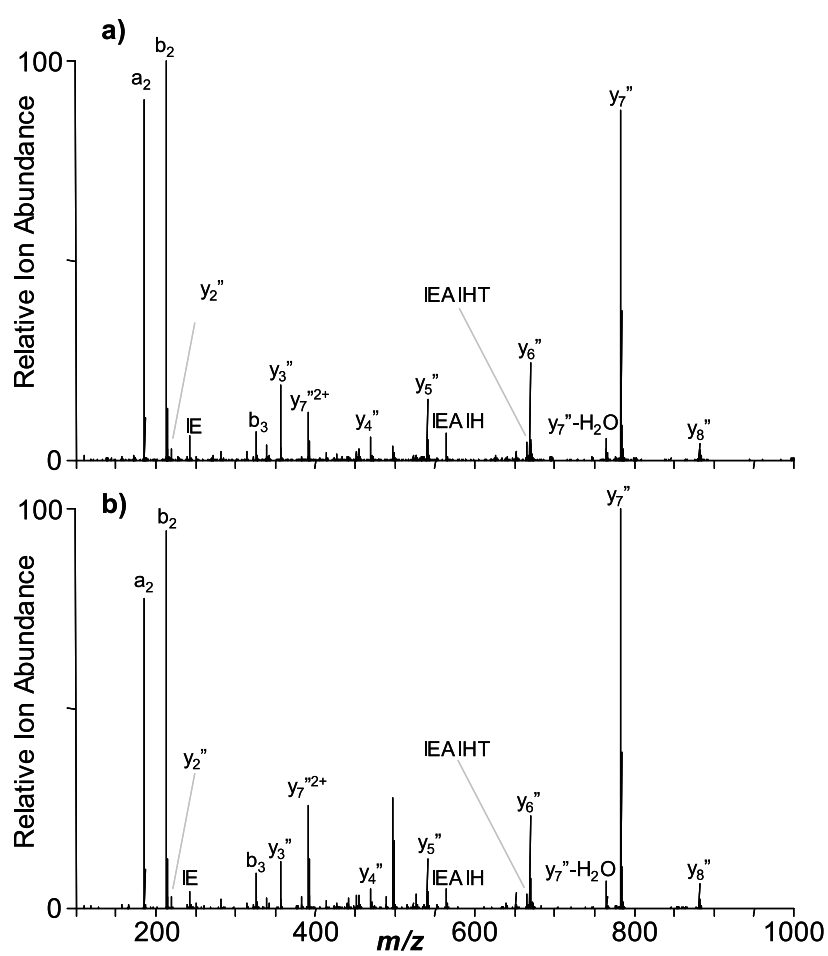

Figure 2. MS/MS spectra from (a) a naturally processed peptide isolated from vaccinia-infected B cells and (b) synthesized peptide with the sequence IVIEAIHTV, a sequence from TmpK that is

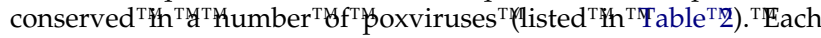
spectrum was acquired with a collision energy of $-18 \mathrm{~V}$.

despite the presence of a strong $y$-ion series, the

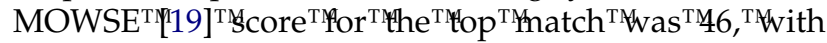
thresholds of 56 for similarity and 68 for identity. In addition, the top five matches all had the same score. In particular, the sequence IVLEAIAEH from phospholipase $C \beta 3$ gave the same score and also equally accounted for the major fragment ions observed in the spectrum. Only three minor fragment ions, marked

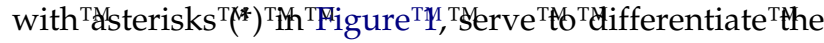
sequence of IVIEAIHTV from IVLEAIAEH.

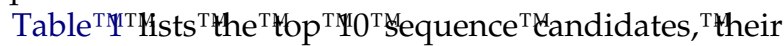
chemical formula, MOWSE score, and $\mathrm{m} / \mathrm{z}$ of their doubly charged ion. Candidate sequences 3-10 can be

Table 1. List of top 10 most closely matched peptide sequences from a MASCOT search of an MS/MS spectrum from a Q-Tof II

\begin{tabular}{lccccc}
\hline Sequence & Chemical formula & MOWSE score & $\mathrm{M}_{\mathrm{r}}$ & {$\left[\mathrm{M}+2 \mathrm{H}^{+}\right]^{2+}$} & $\Delta m / z(\mathrm{ppm})$ \\
\hline \hline IVIEAIHTV & $\mathrm{C}_{45} \mathrm{H}_{79} \mathrm{~N}_{11} \mathrm{O}_{13}$ & 46.4 & 993.58588 & 497.80022 & -0.8 \\
IVLEAIAEH & $\mathrm{C}_{45} \mathrm{H}_{75} \mathrm{~N}_{11} \mathrm{O}_{14}$ & 46.4 & 993.54950 & 497.78203 & -37.3 \\
LVLESPSHI & $\mathrm{C}_{45} \mathrm{H}_{75} \mathrm{~N}_{11} \mathrm{O}_{14}$ & 46.4 & 993.54950 & 497.78203 & -37.3 \\
IVIESPIHS & $\mathrm{C}_{45} \mathrm{H}_{75} \mathrm{~N}_{11} \mathrm{O}_{14}$ & 46.4 & 993.54950 & 497.78203 & -37.3 \\
IVLELACYA & $\mathrm{C}_{46} \mathrm{H}_{75} \mathrm{~N}_{9} \mathrm{O}_{13} \mathrm{~S}_{1}$ & 46.4 & 993.52051 & 497.76753 & -66.4 \\
LVLEVNNPP & $\mathrm{C}_{45} \mathrm{H}_{75} \mathrm{~N}_{11} \mathrm{O}_{14}$ & 42.1 & 993.54950 & 497.78203 & -37.3 \\
LVLELLTHG & $\mathrm{C}_{46} \mathrm{H}_{79} \mathrm{~N}_{11} \mathrm{O}_{13}$ & 42.1 & 993.58588 & 497.80022 & -0.8 \\
LVIDVELPP & $\mathrm{C}_{47} \mathrm{H}_{79} \mathrm{~N}_{9} \mathrm{O}_{14}$ & 36.5 & 993.57465 & 497.79460 & -12.1 \\
LVLDVEIHG & $\mathrm{C}_{45} \mathrm{H}_{75} \mathrm{~N}_{11} \mathrm{O}_{14}$ & 36.5 & 993.54950 & 497.78203 & -37.3 \\
LVLTLVLSH & $\mathrm{C}_{47} \mathrm{H}_{83} \mathrm{~N}_{11} \mathrm{O}_{12}$ & 34.2 & 993.62227 & 497.81841 & 35.8 \\
\hline
\end{tabular}

Spectrum shown in Figure 1a. The right column lists the deviation in mass of each of the sequences relative to an experimental result of 497.8006 obtained on a hybrid FTICR-MS instrument. Candidate sequences 3-10 can be more readily distinguished by the MS/MS data. 
Table 2. Conservation of the naturally processed and presented class I HLA-A*0201 vaccinia-derived peptide IVIEAIHTV among poxviruses causing infection in humans

\begin{tabular}{|c|c|c|c|c|}
\hline Orthopox & $\begin{array}{c}\text { GenBank } \\
\text { accession no. }\end{array}$ & Gene name & Protein ID & Protein name \\
\hline \multicolumn{5}{|l|}{ Vaccinia virus } \\
\hline Modified vaccinia Ankara (MVA) & U94848 & MVA161R & AAB96539.1 & thymidylate kinase (TmpK) \\
\hline Copenhagen & M35027 & A48R & AAA48180.1 & CDS A48R, putative \\
\hline Tian Tan & AF095689 & TA59R & AAF34060.1 & AAF34060.1 protein \\
\hline Western reserve (WR) & & VACWR174 & AA089453.1 & TmpK \\
\hline \multicolumn{5}{|l|}{ Variola major } \\
\hline Bangladesh-1975 & ML22579 & $\mathrm{J} 2 \mathrm{R}$ & AAA60903.1 & $\begin{array}{l}\text { homolog of vaccinia virus } \\
\text { CDS A48R (TmpK) }\end{array}$ \\
\hline India-1967 & MX69198 & $\mathrm{J} 2 \mathrm{R}$ & CAA49101.1 & NA \\
\hline \multicolumn{5}{|l|}{ Variola minor } \\
\hline Garcia-1966 & MY16780 & $\mathrm{K} 2 \mathrm{R}$ & CAB54761.1 & $\mathrm{K} 2 \mathrm{R}$ protein \\
\hline \multicolumn{5}{|l|}{ Cowpox virus } \\
\hline Brighton Red & MAF482758 & CPXV186 CDS & AAM13626.1 & CPXV186 protein \\
\hline \multicolumn{5}{|l|}{ Monkeypox } \\
\hline Zaire-96-1-16 & MAF380138 & A49R & AAL40617.1 & similar to Copenhagen A48R \\
\hline \multicolumn{5}{|l|}{ Camelpox } \\
\hline Camelpox M-96 (Kazakhstan) & MAF438165 & $156596 \ldots 157279$ CDS & AAL73876.1 & TmpK \\
\hline
\end{tabular}

eliminated by the $\mathrm{y}_{3}$ and $\mathrm{y}_{4}$ ions, while the $\mathrm{y}_{5}$ and higher $\mathrm{y}$ ions are common to the first seven sequences. The first two candidate sequences differ in doubly charged mass by 0.018 mass units or 36 ppm (36 ppm).

The remainder of SCX fraction 21 was analyzed on a ThermoFinnigan LTQ-FT. Results from this analysis on

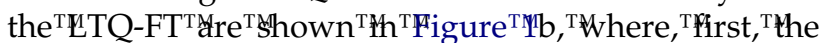
MS/MS spectrum from the LTQ-FT corroborates the

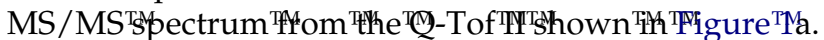

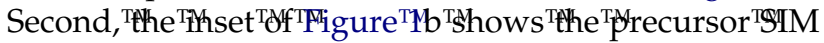
scan from the FTICR analyzer that measured the doubly charged $m / z$ as 497.8006 . The column on the right side of Table ${ }^{\mathrm{T}}{ }^{\mathrm{TT}}$ Msts ${ }^{\mathrm{T}}$ the $\mathrm{T}^{\mathrm{T}}$ deviations ${ }^{\mathrm{T}} \mathrm{O} \mathrm{f}^{\mathrm{T}}$ this ${ }^{\mathrm{T}}$ theasured $\mathrm{T}^{\mathrm{T}} \mathrm{h} / \mathrm{z}$ from the theoretical $\mathrm{m} / \mathrm{z}$ values for each of the top 10 candidate sequences. The measured $\mathrm{m} / \mathrm{z}$ is within $0.8 \mathrm{ppm}$ of the calculated mass of IVIEAIHTV from vaccinia but is 37.3 ppm from the alternate sequence IVLEAIAEH from phospholipase $C \beta 3$. The seventh candidate sequence

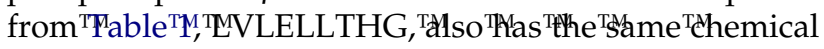
formula as IVIEAIHTV; however, the $\mathrm{y}_{2}, \mathrm{y}_{3}$, and $\mathrm{y}_{4}$ ions from the tandem mass spectra serve to distinguish between the two sequences.

Because peptides presented by class I and II HLA molecules are not C-terminally constrained to Arg, Lys, or the protein C-terminus, many more candidate sequences will pass initial precursor ion mass filtering, to be subsequently scored on the basis of matching fragment ions. Although accurate mass precursor ion data alone can not definitively identify these peptides, it greatly decreases the number of candidate sequences to be matched against the fragment ion data. When this MS/MS spectrum is searched using a precursor tolerance of $20 \mathrm{ppm}$, the only match is IVIEAIHTV from vaccinia. It is noted that methylation of acidic residues followed by reanalysis also would serve to differentiate these two sequences at the cost of the additional derivitization procedure and its potential for further sample loss.
To frame this accurate mass result within the context of other identified peptides, we calculated the accurate mass deviations for six additional peptides. Five of six results ranged from less than 0.1 to $1.2 \mathrm{ppm}$ mass error, consistent with results we have observed for tryptic peptides (data not shown). The sixth peptide's precursor mass was $-15.7 \mathrm{ppm}$ from the proposed sequence. The MOWSE score for this peptide was 40 ( $>40$ for homology, $>50$ for identity). Inspection of the match results from this peptide showed that six of the nine fragment ions with greater than $50 \%$ relative abundance were not matched, strongly suggesting the proposed sequence was incorrect. The MOWSE score did not differentiate this false positive result from other results of similar MOWSE score, while the mass error of the precursor ion relative to the proposed sequence clearly differentiated this incorrect search result from the other peptides in this set.

We also had the peptide IVIEAIHTV synthesized, which was then analyzed by LC-MS/MS on our Q-Tof-

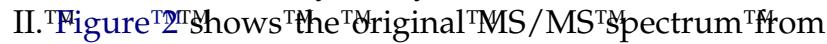
the naturally processed peptide (upper trace) compared with the MS/MS spectrum from the synthesized peptide, showing the close agreement in fragmentation patterns and again confirming our identification.

When we looked at other orthopoxviruses, we observed that this epitope, IVIEAIHTV, is highly conserved in vaccinia, variola, cowpox, monkeypox, and

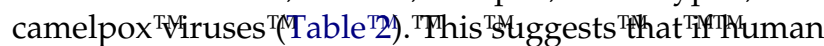
CTL will recognize this epitope, they will most likely recognize variola virus-infected cells as well. Because this epitope is endogenously processed and presented on HLA-A2 molecules of infected cells, one can hypothesize that $\mathrm{CD}^{+} \mathrm{T}$ cells raised by immunization and restimulation with this peptide will most likely recognize cells infected with vaccinia virus. Thus, it may be possible to develop a new peptide-based smallpox 
vaccine based on a combination of naturally processed and presented vaccinia peptides.

\section{Conclusion}

We have used accurate mass measurement of the precursor ion in conjunction with MS/MS to identify a novel HLA class I peptide from a vaccinia protein that is presented after infection of $B$ cells with live vaccinia virus. The MS/MS data, in conjunction with accurate mass data for the precursor ion, identifies the peptide as IVIEAIHTV from the TmpK protein of vaccinia virus. The combination of 2D-LC for peptide separation, with MS/MS and precursor ion accurate mass data, is a powerful tool for identifying naturally processed peptides presented by the HLA pathway. In the examples reported here for naturally processed peptides lacking the C-terminal amino acid restraints of a tryptic or Lys- $C$ generated peptide, accurate mass has been used to both augment fragmentation data and as a means of discovering false positives from database search results.

\section{Acknowledgments}

The authors thank Diana Ayerhart for her help in preparing this article and Richard Kennedy, Jenna Ryan, and Norman Pinsky for growing vaccinia virus and performing cell cultures. Funding for this work was provided by Mayo Clinic and National Institutes of Health (NIH) grants AI53592 and AI33144, and NIH grant AI57153 through the Great Lakes Regional Center of Excellence for Biodefense and Emerging Infectious Diseases Research (GLRCE).

\section{References}

1. Fenn, J. B.; Mann, M.; Meng, C. K.; Wong, S. F.; Whitehouse, C. M. Electrospray Ionization for Mass Spectrometry of Large Biomolecules. Science 1989, 246, 64-71.

2. Moseley, M. A.; Deterding, L. J.; Tomer, K. B.; Jorgenson, J. W. Nanoscale Packed-Capillary Liquid Chromatography Coupled with Mass Spectrometry Using a Coaxial ContinuousFlow Fast Atom Bombardment Interface. Anal. Chem. 1991, 63, 1467-1473.

3. Emmett, M. R.; Caprioli, R. M. Micro-Electrospray MassSpectrometry-Ultra-High-Sensitivity Analysis of Peptides and Proteins. J. Am. Soc. Mass Spectrom. 1994, 5, 605-613.

4. Hunt, D. F.; Henderson, R. A.; Shabanowitz, J.; Sakaguchi, K.; Michel, H.; Sevilir, N.; Cox, A. L.; Appella, E.; Engelhard, V. H. Peptides Presented to the Immune System by the Murine Class II Major Histocompatibility Complex Molecule I-Ad. Science 1992, 255, 1261-1263.

5. Link, A. J.; Eng, J.; Schieltz, D. M.; Carmack, E.; Mize, G. J.; Morris, D. R.; Garvik, B. M.; Yates, J. R. III. 3rd Direct Analysis of Protein Complexes Using Mass Spectrometry. Nat. Biotechnol. 1999, 17, 676-682.

6. Washburn, M. P.; Wolters, D.; Yates, J. R. III. 3rd Large-Scale Analysis of the Yeast Proteome by Multidimensional Protein Identification Technology. Nat. Biotechnol. 2001, 19, 242-247.

7. Ovsyannikova, I. G.; Johnson, K. L.; Naylor, S.; Muddiman, D. C.; Poland, G. A. Naturally Processed Measles Virus Peptide Eluted from Class II HLA-DRB1*03 Recognized by T Lymphocytes from Human Blood. Virology 2003, 312, 495-506.

8. Ovsyannikova, I. G.; Johnson, K. L.; Muddiman, D. C.; Vierkant, R. A.; Poland, G. A. Identification and Characterization of Novel, Naturally Processed Measles Virus Class II HLADRB1 Peptides. J. Virol. 2004, 78, 42-51.

9. Ovsyannikova, I. G.; Johnson, K. L.; Naylor, S.; Poland, G. A. Identification of HLA-DRB1-Bound Self-Peptides Following Measles Virus Infection. J. Immunol. Methods 2005, 297, 153-167.

10. Hunt, D. F.; Shabanowitz, J.; Yates, J. R. III; McIver, R. T. Jr.; Hunter, R. L.; Syka, J. E.; Amy, J. Tandem Quadrupole-Fourier Transform Mass Spectrometry of Oligopeptides. Anal. Chem. 1985, 57, 2728-2733.

11. Syka, J. E.; Marto, J. A.; Bai, D. L.; Horning, S.; Senko, M. W.; Schwartz, J. C.; Ueberheide, B.; Garcia, B.; Busby, S.; Muratore, T.; Shabanowitz, J.; Hunt, D. F. Novel Linear Quadrupole Ion Trap/FT Mass Spectrometer: Performance Characterization and Use in the Comparative Analysis of Histone H3 PostTranslational Modifications. J. Proteome Res. 2004, 3, 621-626.

12. Smith, R. D.; Anderson, G. A.; Lipton, M. S.; Pasa-Tolic, L.; Shen, Y.; Conrads, T. P.; Veenstra, T. D.; Udseth, H. R. An Accurate Mass Tag Strategy for Quatitative and HighThroughout Proteome Measurements. Proteomics 2002, 2, 513 523.

13. Olsen, J. V.; Ong, S. E.; Mann, M. Trypsin Cleaves Exclusively C-Terminal to Arginine and Lysine Residues. Mol. Cell Proteomics 2004, 3, 608-614.

14. Drexler, I.; Staib, C.; Kastenmuller, W.; Stevanovic, S.; Schmidt, B.; Lemonnier, F. A.; Rammensee, H. G.; Busch, D. H.; Bernhard, H.; Erfle, V.; Sutter, G. Identification of Vaccinia Virus Epitope-Specific HLA-A*0201-Restricted T Cells and Comparative Analysis of Smallpox Vaccines. Proc. Natl. Acad. Sci. U. S. A. 2003, 100, 217-222.

15. Snyder, J. T.; Belyakov, I. M.; Dzutsev, A.; Lemonnier, F.; Berzofsky, J. A. Protection Against Lethal Vaccinia Virus Challenge in HLA-A2 Transgenic Mice by Immunization with a Single CD8 + T-Cell Peptide Epitope of Vaccinia and Variola Viruses. J. Virol. 2004, 78, 7052-7060.

16. Mathew, A.; Terajima, M.; West, K.; Green, S.; Rothman, A. L.; Ennis, F. A.; Kennedy, J. S. Identification of Murine PoxvirusSpecific CD8 + CTL Epitopes with Distinct Functional Profiles. J. Immunol. 2005, 174, 2212-2219.

17. Moss, B. Reproduction of Poxviruses. Compr Virol 1974, 3, 405-474.

18. Goebel, S. J.; Johnson, G. P.; Perkus, M. E.; Davis, S. W.; Winslow, J. P.; Paoletti, E. The Complete DNA Sequence of Vaccinia Virus. Virology 1990, 179, 247-266.

19. Perkins, D. N.; Pappin, D. J.; Creasy, D. M.; Cottrell, J. S. Probability-Based Protein Identification by Searching Sequence Databases Using Mass Spectrometry Data. Electrophoresis 1999, 20, 3551-3567.

20. Ellis, J. M.; Henson, V.; Slack, R.; Ng, J.; Hartzman, R. J.; Katovich Hurley, C. Frequencies of HLA-A2 Alleles in Five U.S. Population Groups. Predominance of $A^{*} 02011$ and Identification of HLA-A*0231. Hum. Immunol. 2000, 61, 334-340.

21. Bjorkman, P. J.; Saper, M. A.; Samraoui, B.; Bennett, W. S.; Strominger, J. L.; Wiley, D. C. Structure of the Human Class I Histocompatibility Antigen, HLA-A2. Nature 1987, 329, 506512.

22. Sidney, J.; Southwood, S.; Mann, D. L.; Fernandez-Vina, M. A.; Newman, M. J.; Sette, A. Majority of Peptides Binding HLAA*0201 with High Affinity Crossreact with Other A2-Supertype Molecules. Hum. Immunol. 2001, 62, 1200-1216.

23. Kubo, R. T.; Sette, A.; Grey, H. M.; Appella, E.; Sakaguchi, K.; Zhu, N. Z.; Arnott, D.; Sherman, N.; Shabanowitz, J.; Michel, H. Definition of Specific Peptide Motifs for Four Major HLA-A Alleles. J. Immunol. 1994, 152, 3913-3924.

24. Hughes, S. J.; Johnston, L. H.; de Carlos, A.; Smith, G. L. Vaccinia Virus Encodes an Active Thymidylate Kinase that Complements a cdc8 Mutant of Saccharomyces cerevisiae. J. Biol. Chem. 1991, 266, 20103-20109. 